\title{
Spatial and Temporal Features of Regional Variations in Mean Sea Level around Taiwan
}

\author{
Li-Chung $\mathrm{Wu}^{1}$, Chia Chuen Kao ${ }^{2}$, Tai-Wen Hsu ${ }^{2 *}$, Yi-Fung Wang ${ }^{3}$, Jong-Hao Wang ${ }^{3}$ \\ ${ }^{1}$ Coastal Ocean Monitoring Center, National Cheng Kung University, Tainan, Chinese Taipei \\ ${ }^{2}$ Department of Hydraulic and Ocean Engineering, National Cheng Kung University, Tainan, Chinese Taipei \\ ${ }^{3}$ Water Resources Agency, Ministry of Economic Affairs, Taipei, Chinese Taipei \\ Email: ${ }^{*}$ twhsu@mail.ncku.edu.tw
}

Received January 10, 2012; revised March 9, 2012; accepted March 18, 2012

\begin{abstract}
Satellite altimeter and in-situ tide gauge records are probably the most common means to obtain observational data for the study of changes in mean sea level. In this study, we employed these data to discuss the spatial and temporal features of regional variations in mean sea level around Taiwan. The results showed that most of the regional mean sea surface heights (SSH) around Taiwan are higher than the global mean sea surface heights. Most of the sea level trends are greater than the global mean sea level trend as well. We obtained diverse distribution results from the altimeter sea level records in neighboring areas by distributions fit, and the altimeter sea level records showed obvious inhomogeneity. In addition, periodic fluctuations in the records regarding mean sea level were revealed in our study, based on Fourier spectra and wavelet scalograms.
\end{abstract}

Keywords: Sea Level Variations; Tide-Gauge; Altimeter

\section{Introduction}

The United Nations estimates that by 2004, more than $75 \%$ of the world's population was living within the coastal zone, and the importance of these regions extends to their influence on global economic activities [1]. Because several million people live in coastal areas that are less than 10 meters above sea level, the features of sea level are a critical factor in the development of humankind. Sea levels fluctuate due to natural phenomena, such as wind waves, swell, tsunamis, astronomical tides, storm surges, and other various factors. In addition, atmospheric pressure, ocean currents, and changes in local ocean temperatures can also influence variations in mean sea level. In recent years, thermal expansion of the oceans was expected to be a dominant factor behind increases in sea level [2]. For extremely mild slope coastal areas, even a small increase in sea level could result in a serious threat to coastal environments. Indications of global warming revealed through various atmospheric and oceanic records are pushing the discussion of longterm changes in sea levels to the forefront of the global research community.

Taiwan is an island located at the western edge of the Pacific Ocean, lying on the border between the largest land mass and the largest ocean in the world. The coast-

${ }^{*}$ Corresponding author. line around Taiwan covers a total length of over one thousand kilometers, and the surrounding bathymetry is highly complicated. Along the east coast of Taiwan, the seafloor drops rapidly to thousands of meter in depth from the coastline, with a slope in this area of approximately $1 / 10$. Compared to the eastern Taiwan, the slope (about $1 / 100-1 / 50$ ) along the west coast is relatively mild. In some areas of west coast, the slope can be milder than $1 / 1500$. Due to the potential impact on the coastal environment, understanding the features of sea level variation around Taiwan is an issue of great concern.

This study focuses on the phenomenon of long-term variations in sea level and in-situ sea level records from coastal tide stations are ideally suited to such research. Church and White [3] pointed that global mean sea levels have risen an average of approximately $1.7 \mathrm{~mm} /$ year and a significant acceleration in the rise of sea-levels of approximately $0.013 \mathrm{~mm} / \mathrm{year}^{2}$. To accurately evaluate the rate of change in sea levels, the effects of tectonic movements or local subsidence upon the measurement of mean sea level has to be taken into consideration. It is essential to adjust perceived changes in mean sea level to account for vertical movements of the land, which may be of the same order as changes in the sea level around Taiwan or even higher [4]. However, most of the benchmark tide gauges were not corrected in the former time and the actual magnitude of land subsidence was practi- 
cally unknown. It is difficult to identify trends in the changes of sea levels using uncorrected tide gauge records. Since the 1990s, satellite altimetry has provided most of the information regarding regional sea levels both in Taiwan and globally. Satellite altimetry determines the distance from the satellite to the surface of the sea by measuring the satellite-to-surface round-trip time of a radar pulses. Previous studies presented changes in global mean sea levels based on the Topex-Poseidon altimetry data $[5,6]$.

A large number of studies have revealed the features of global sea level change by discussing altimeter records; however, the issue of regional sea level characteristics has received little attention. With respect to the land, mean sea level is a relatively stable surface value; however, it varies irregularly in the time and space domain. The aim of this study was to discuss the spatial and temporal features of variations in regional sea levels around Taiwan. Results of statistical and spectral analysis are presented in our study, to confirm the local features of sea level variation in Taiwanese waters.

\section{Data Source}

Satellite altimeter and in-situ tide gauge records are probably the most common means to obtain observational data for the study of changes in mean sea level. White et al. [7] used satellite and in-situ data to discuss coastal and global averaged sea level rise. In our study, we focus on the local features of sea level around Taiwan. To evaluate the spatial features of sea levels in Taiwanese waters, we used altimeter data from the merged geophysical data (MGDRB) records. The altimeter products were produced by Ssalto/Duacs and distributed by Aviso [8]. Sea level anomalies (SLA) describe variations in sea surface height (SSH) with respect to a mean sea surface (MSS). The SSH is the height of the sea surface with respect to a reference ellipsoid, and MSS information provides the ocean surface averaged vertical position over a period of time. The spatial resolution of SLA was resampled on a $1 / 4^{\circ} \times 1 / 4^{\circ}$ Cartesian grid. In addition to the spatial resolution, temporal resolution had to be considered. The temporal resolution of SLA from the altimeter record was 7 days. To obtain accurate sea level data, the influence of atmosphere and ionosphere upon the velocity of altimeter radio pulses also had to be considered. The sea level data from Aviso had already been corrected by propagation, ocean surface, and geophysical and atmospheric corrections. Error due to the atmosphere through which the radar pulse travels and the nature of the reflecting surface also had to be corrected.

The data used in our analysis comprised more than 15 years of altimetry data (1993-2008). The selection of spatial altimeter records around Taiwan is shown in Fig- ure 1. Because the west coast of Taiwan is a $200-\mathrm{km}-$ wide shallow passage, it is impossible to select a large area that is not affected by the edges of Mainland China or Taiwan. Here we selected nine grids in each local area of the sea. These nine grids were arrayed as a $3 \times 3$ matrix, to address the spatial features of altimeter records from neighboring grids. Four different record matrices were selected from the sea areas around Taiwan. Because these four matrices are located north, east, west, and south of Taiwan, these matrices were named $\boldsymbol{M}_{N}, \boldsymbol{M}_{\boldsymbol{E}}$, $\boldsymbol{M}_{W}$, and $\boldsymbol{M}_{\boldsymbol{S}}$ in the following sections. In addition, the sea level data from four different in-situ tide stations (Keelung, Fugang, Taichung, and Xunguangzui) was also collected in this study. It should be noted that the locations of these in-situ tide stations was close to altimeter record matrices. To obtain accurate sea level information, the effects of surface atmospheric pressure on low frequency sea level variability had to be removed [9]. The altimeter records were corrected by the ECMWF model. The in-situ sea surface data from four different in-situ tide stations were corrected by the in-situ air pressure data, this method was proposed by Wunsch and Stammer [10].

\section{Data Analysis}

\subsection{Statistical Features of Regional Sea Level}

Figure 2 presents altimeter sea level data observed in several areas of the sea. It appears that the sea levels are increasing in these areas. As previously mentioned, we selected nine grids from the altimeter records in each local sea area. These nine grids were arrayed as a $3 \times 3$

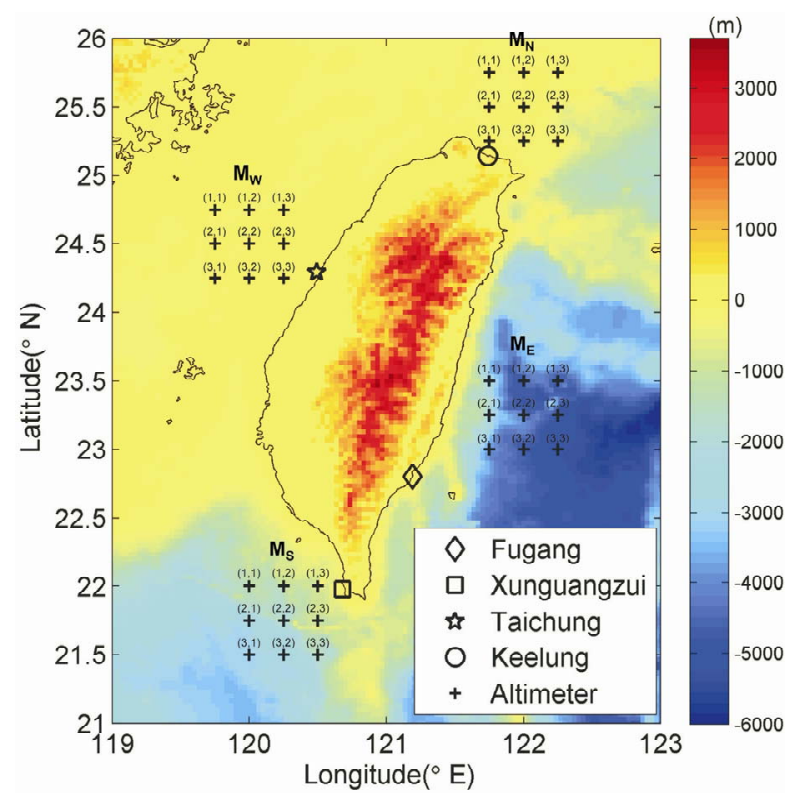

Figure 1. Locations of data sets obtained from altimeter and in-situ tide stations. 

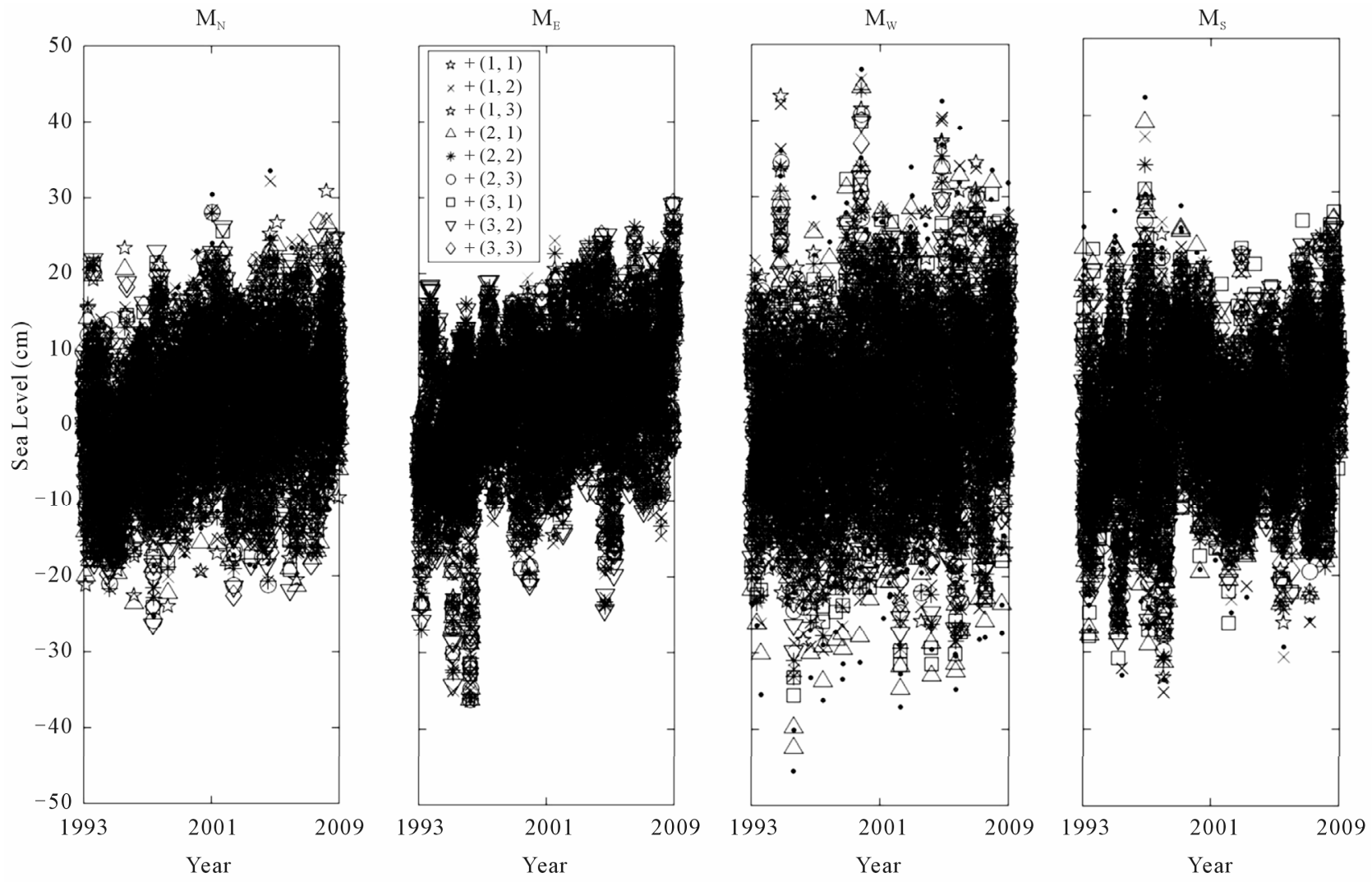

Figure 2. Sea level records from altimeter data.

matrix, the location $(I, J)$ indicates the element at the $I$-th row and the $J$-th column. The rate of change in the sea level calculated in different areas is presented in Figure 3 , revealing that increases in sea level in the same area were uniform. However, differences in sea level rise rates in various areas around Taiwan can be as high as 5 $\mathrm{mm} /$ year. This indicates obvious spatial inhomogeneity in the altimeter records among various regions of the sea around Taiwan. Homogeneity means that the statistical properties do not change with space; and inhomogeneity implies instability in the statistical properties of the space domain. Figure 3 also presents calculated sea level trends from in-situ tide gauge records. Because the in-situ tide stations at Keelung, Fugang, Taichung, and Xunguangzui are close to the sea areas of $\boldsymbol{M}_{N}, \boldsymbol{M}_{E}, \boldsymbol{M}_{W}$, and $\boldsymbol{M}_{\boldsymbol{S}}$ respectively, we used the same designations to present the results from the in-situ data in Figure 3.

Regardless of the results from altimeter or tide gauge records, most of the calculated results of regional sea level trends exceeded $4 \mathrm{~mm} /$ year. Church and White [3] revealed the global average rate of mean sea levels analyzed from in-situ tide records (data records from 1870 to 2004), estimating the increase at $1.7 \mathrm{~mm} /$ year. Ablain et al. [11] presented the global mean sea level rate from altimeter records (data records from 1993 to 2009), estimated at $3.26 \mathrm{~mm} / \mathrm{year}$. The increase in the rate of re- gional sea level trends around Taiwan is greater than global mean sea level trends.

The in-situ records from tide stations in the western and northern parts of Taiwan showed results similar to those calculated from altimeter records. However, the results from eastern and southern in-situ records did not match the results from the altimeter records. In the southern sea area of Taiwan, land subsidence may have been one contributing factor. According to a report from the Taiwanese government [12], the south-west coastal area is one area with the greatest subsidence in Taiwan, due to over use of the local ground water. The maximum accumulated subsidence has been as high as $2.88 \mathrm{~m}$ since 1972. Essentially, the influences of subsidence on the bench mark are unavoidable. In addition to the southwest coastal area, the east coast of Taiwan is one of the most actively deforming regions in the world. Yu and Kuo [13] presented evidence of land surface uplift through repeated GPS readings. This is one probable reason that the calculated rate of change in sea levels is lower than the actual rate in the eastern part of Taiwan. From the time series shown in Figure 2, we observe obvious fluctuations in sea level along the west coast of Taiwan. Figure 4 shows the standard deviation in sea level records from various sea areas. The values of standard deviation calculated from different sea areas have 


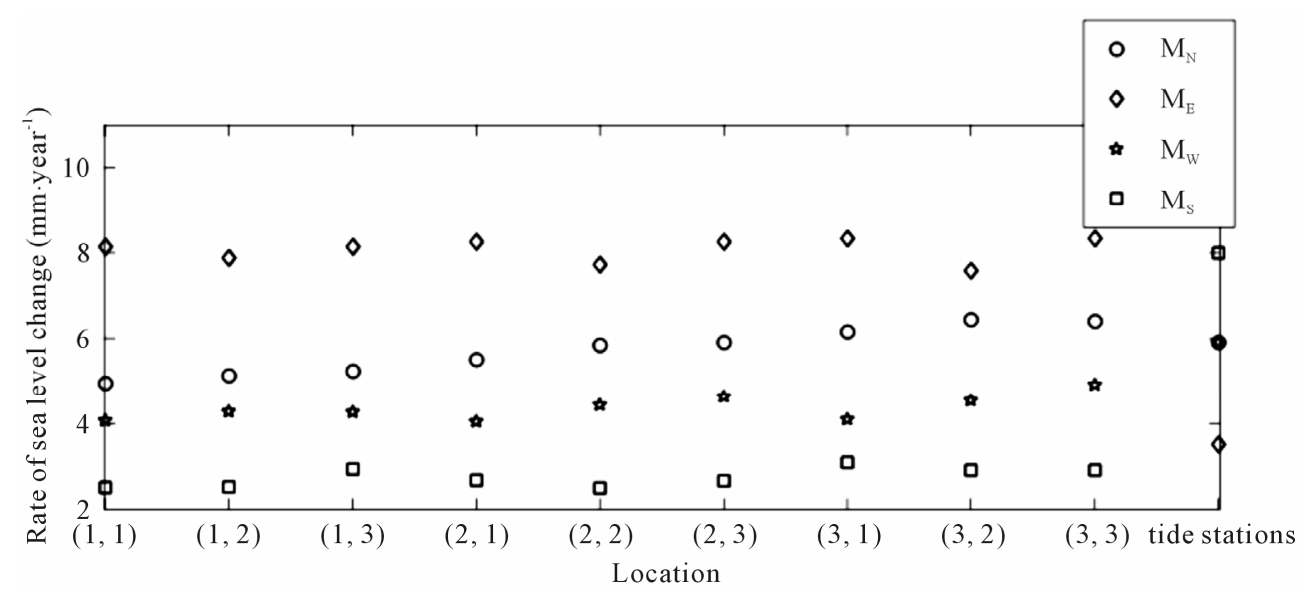

Figure 3. Trends of sea level change around Taiwan.

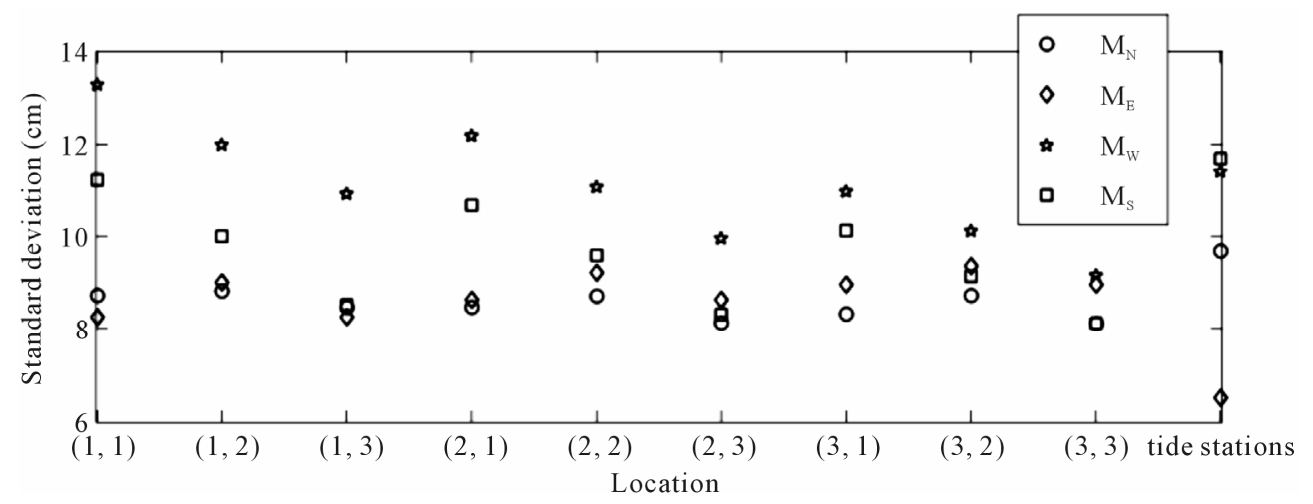

Figure 4. Standard deviation in sea level records.

also shown obvious inhomogeneity, with the values of $\boldsymbol{M}_{\boldsymbol{W}}$ exceeding those in other sea areas. It should be noted that tidal differences within the Taiwan Strait are larger than other areas around Taiwan. The influence of such obvious tidal differences is a likely reason for the variations in sea level in the area of $\boldsymbol{M}_{W}$. For the relationship between the results of standard deviation from in-situ observation and remote sensing, the other cases showed similarities in all of the values of calculated standard deviation between altimeter and in-situ tide gauge records except for those in eastern Taiwan.

\subsection{The Distributions of Mean Sea Level Records}

Probability distribution based on the stochastic process provides a key to evaluating various characteristics of sea level. The distribution functions of Beta, Normal, Chisquared, Log-gamma, Logistic, Rayleight, Weibull, Generated Extreme Values were used to determine the ideal distribution in every sea level time series. We employed the chi-squared test for the goodness of fit. Depending on the chosen goodness of fit tests, we calculated the chisquared test for each of the fitted distributions. If the chi-squared test were unable to reject impractical distribution functions, the minimal differences between the selected distribution function and the distribution of sea level data would be used to determine the distribution function with the best fit. Table 1 presents the fitted distribution functions of sea level records. Most of the sea level records from various in-situ tide stations showed Generalized Extreme Value distributions. However, we often obtained different distributions from the altimeter records within the matrix in the same sea areas, particularly for those within $\boldsymbol{M}_{W}$. We obtained five different distribution functions from nine elements of $\boldsymbol{M}_{\boldsymbol{W}}$. The results of distribution fitness once again showed spatial non-homogeneity of altimeter sea level records. We evaluated the mean, skewed values of various distributions fitted from the time series of sea level records. In Figure 5, the value of zero on the y-axis indicated the sea surface height averaged across all the oceans of the globe. Figure 5 illustrates that most of the sea surface heights observed around Taiwan were higher than the global mean surface height. The records from the east coast of Taiwan showed higher sea surface height than the records from other sea areas. The regional sea surface height along the south coast of Taiwan was closer to the 
global mean. Because the benchmarks between altimeter and in-situ tide records were different, the mean values of in-situ records are not presented in Figure 5. Figure 6 shows that most of the calculated skewness values from $\boldsymbol{M}_{\boldsymbol{N}}$ and $\boldsymbol{M}_{\boldsymbol{S}}$ were close to zero, indicating that sea surface height distribution in these two sea areas was more symmetric. However, the distribution of sea surface height in the east sea area showed obvious negative skewness.

\subsection{Spectral Features}

As shown in Figure 2, we observed complicated oscilla- tions in all-time series of sea level records. To reveal these oscillations, we applied a spectrum to analyze sea level records. Figure 7 presents the Fourier spectra analyzed from a variety of altimeter and tide gauge records, revealing the peak frequency of 1 year $^{-1}$ comprising most of the sea level records. The fluctuations in sea level were probably influenced by the inverted barometer, even though the altimeter and in-situ sea level records had already been corrected by the ECMWF model and in-situ barometric pressure data, respectively. In addition, the temperature of sea water is likely another main factor

Table 1. Distribution of sea level data.

\begin{tabular}{|c|c|c|c|c|}
\hline & $\mathbf{M}_{\mathbf{N}}$ & $\mathbf{M}_{\mathbf{E}}$ & $\mathbf{M}_{\mathbf{w}}$ & $\mathbf{M}_{\mathbf{S}}$ \\
\hline$(1,1)$ & Normal & Beta & Logistic & Beta \\
\hline$(1,2)$ & Weibull (3P) & Beta & Beta & Normal \\
\hline$(1,3)$ & Normal & Beta & Gen. Extreme Value & Beta \\
\hline$(2,1)$ & Normal & Beta & Logistic & Normal \\
\hline$(2,2)$ & Weibull (3P) & Normal & Normal & Normal \\
\hline$(2,3)$ & Weibull (3P) & Beta & Beta & Normal \\
\hline$(3,1)$ & Weibull (3P) & Beta & Normal & Beta \\
\hline$(3,2)$ & Weibull (3P) & Normal & Normal & Gen. Extreme Value \\
\hline$(3,3)$ & Normal & Beta & Weibull (3P) & Normal \\
\hline Tide station & Gen. Extreme Value & Gen. Extreme Value & Weibull (3P) & Gen. Extreme Value \\
\hline
\end{tabular}

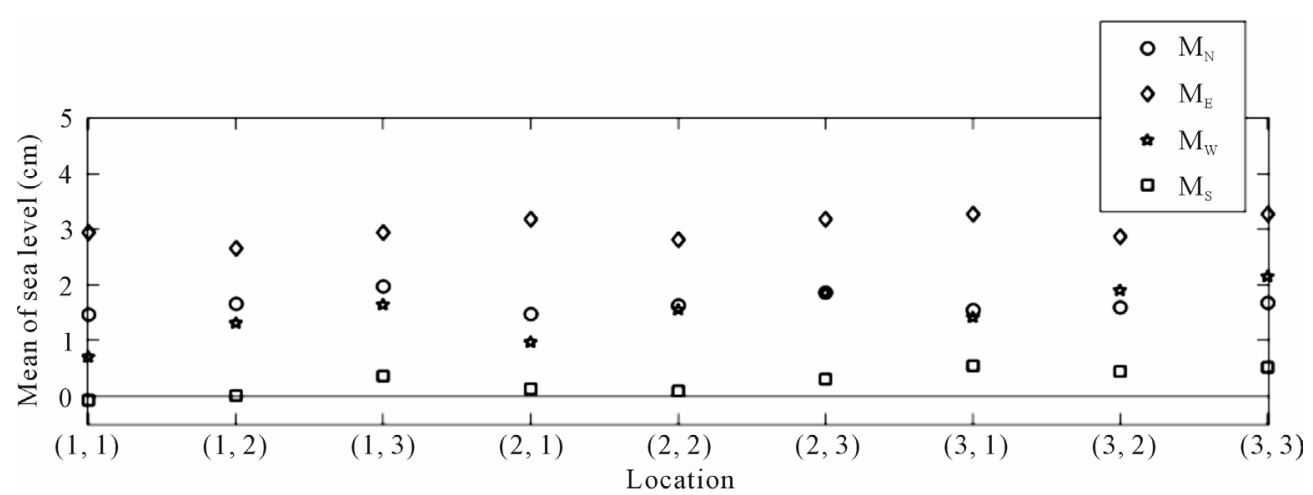

Figure 5. Mean of sea level records.

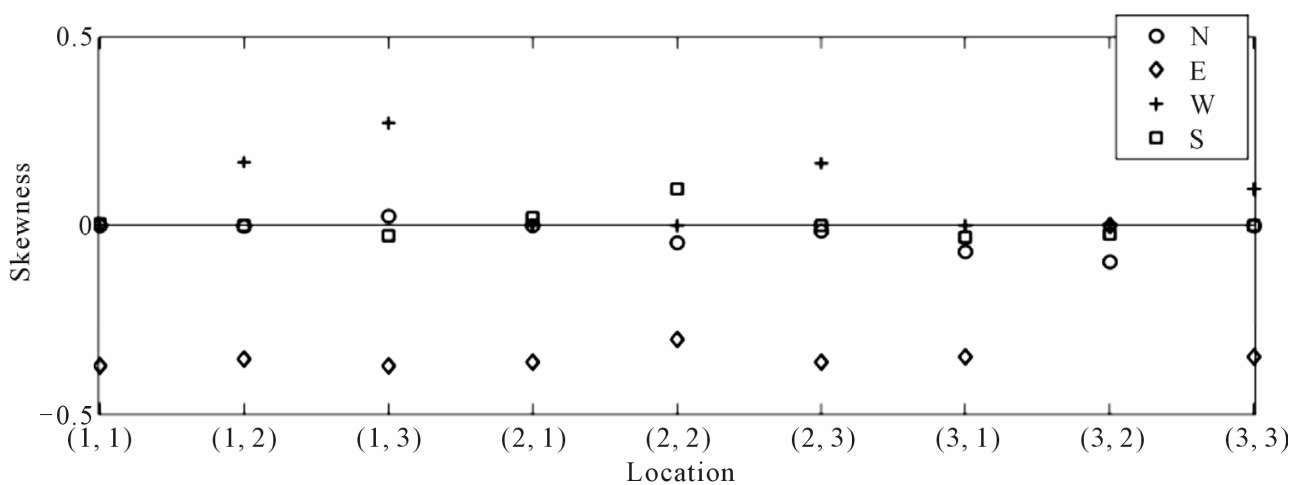

Figure 6. Skewness of sea level distribution. 


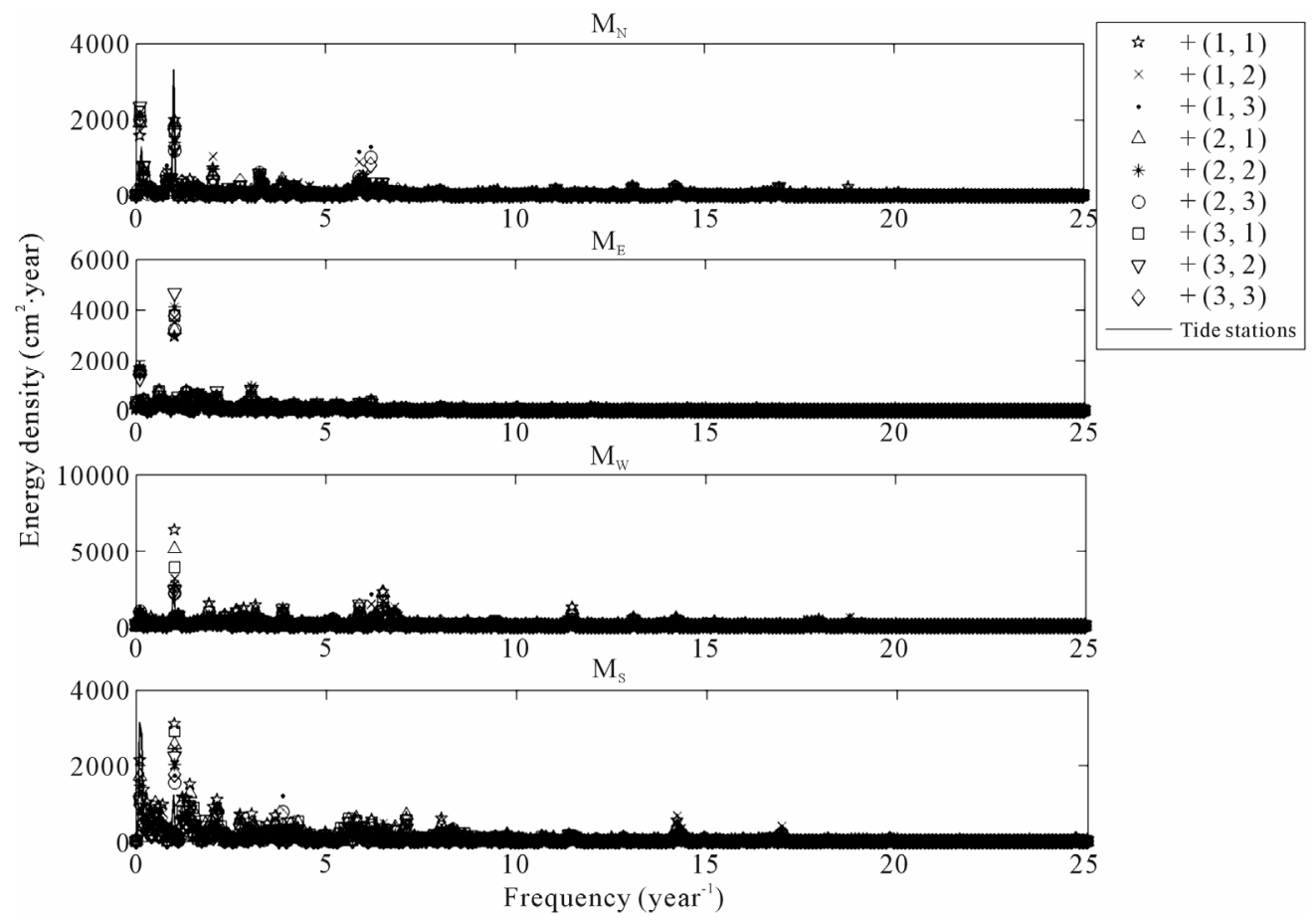

Figure 7. Fourier spectra of sea level data.

influencing the oscillation of sea level. Both air pressure and sea temperature have one year oscillations due to the influences of the seasons. The spectra in Figure 7 also show energy density in some higher frequency bands. The energy density of some astronomical tide constituents can be observed from the Fourier spectra of $\boldsymbol{M}_{W}, \boldsymbol{M}_{\boldsymbol{N}}$ and $\boldsymbol{M}_{\boldsymbol{S}}$, including the lunar monthly constituents (Period $=13.2$ year) and luni-solar fortnightly constituents (Period $=24.7$ year). Unlike the other sea areas, the spectra from $\boldsymbol{M}_{\boldsymbol{E}}$ did not show obvious energy density from the higher frequency band. From most of the Fourier spectra obtained in Taiwan waters, we observed strong energy density located around the frequency bands of 6 year $^{-1}$ and 0.1 year $^{-1}$. This study revealed the bi-monthly and ten-year oscillations of the sea level. In addition to the Fourier spectrum, we investigated non-stationary features of sea level time series by wavelet scalogram. Wavelet transform is similar to Fourier transform in that it breaks signals into their constituents. However, the wavelet scalogram provides extra resolution to the signal energy in the time domain as well as the frequency domain. It is a useful tool for determining the oscillation of sea level records both in the time and frequency domain simultaneously. To implement the wavelet algorithm, it is necessary to choose a mother wavelet function first. We selected the Morlet wavelet function, commonly used in spectrum analysis $[14,15]$, to identify sea surface information from the altimeter records. It should be mentioned that the wavelet scalogram presents the time-frequency variations of spectral components, but at a dif- ferent time-frequency resolution. For the low frequency information from the wavelet scalogram, the time resolution is poor but frequency resolution is high. When it is shifted toward high frequencies, the time resolution increases but the frequency resolution decreases. This is very similar to the Heisenberg Uncertainty Principle [16]. We obtained various results from the wavelet scalogram for each element of the altimeter matrix. In other words, 36 different scalogram results were calculated from four different sea areas around Taiwan. The features of wavelet scalograms from the nine elements of each altimeter record matrix were similar. We averaged the sea level records from nine grids of each matrix. Based on the results of wavelet scalograms from various sea areas (Figure 8), we revealed the non-stationarity in the time series of the altimeter records. The energy density in the frequency band of 1 year $^{-1}$ did not stabilize within the entire time domain. For the results from northern sea areas, the 1-year oscillation was more obvious during 1997-1999 and 2002-2005 than that during other years. It should be noted that the 1-year oscillations in different sea areas were dissimilar. Compared to the results from Fourier spectra, we observed clear energy density from the high frequency bands of the wavelet scalogram. The distribution of high frequency energy density was also non-stationary. Most of the high frequency energy density occurred in the summer and autumn. Similar to the results from the Fourier spectrum, we also observed the energy of lunar monthly constituents (Period $=13.2$ year) from the wavelet scalogram of different sea areas. However, 
the energy density in the frequency band did not stabilize within the entire time domain. We applied the non-stationarity index, to verify and determine the degree of the non-stationarity from different kinds of time series of sea level records. The theory behind the non-stationarity index was proposed by Liu [17], based on the wavelet scalogram. The non-stationarity Index $\left(N_{I}\right)$ was defined as:

$$
\begin{gathered}
N_{I}=\sum_{i} \sum_{j}\left\{W\left(f_{i}, t_{j}\right)-\Phi\left(f_{i}\right) / \Phi\left(f_{i}\right)\right\}^{2} \\
\Phi\left(f_{i}\right)=\left[\sum_{j=1}^{T} W\left(f_{i}, t_{j}\right)\right] / T
\end{gathered}
$$

where $W\left(f_{i}, t_{j}\right)$ is the wavelet scalogram, $f_{i}$ is the frequency bins, $t_{j}$ is the time, $T$ is the total number of data points. Based on Equation (1) and Equation (2), a time series with a larger $N_{I}$ is likely to be more non-stationary than ones whose $N_{I}$ is smaller. Figure 9 presents the cal- culated results of the non-stationarity index from the sea level records in different sea areas. The longer the sea level records were, the higher of the non-stationarity index was. Figure 9 also shows that the results of the nonstationarity index were higher in the sea area of $\boldsymbol{M}_{\boldsymbol{E}}$ and lower in the sea area of $\boldsymbol{M}_{\boldsymbol{W}}$. Figure 9 reveals that the oscillations of sea level within the sea area of $\boldsymbol{M}_{\boldsymbol{W}}$ were more stationary than in other sea areas.

\section{Conclusions}

The trends associated with changes in sea level have been a topic of particular concern since scientists first noticed signs of global warming. Due to obvious differences in bathymetry between the west and east coasts of Taiwan, understanding the regional sea level patterns around the island is essential to characterizing the phenomenon of sea level change. This study investigated the statistical and spectral characteristics of sea level in the
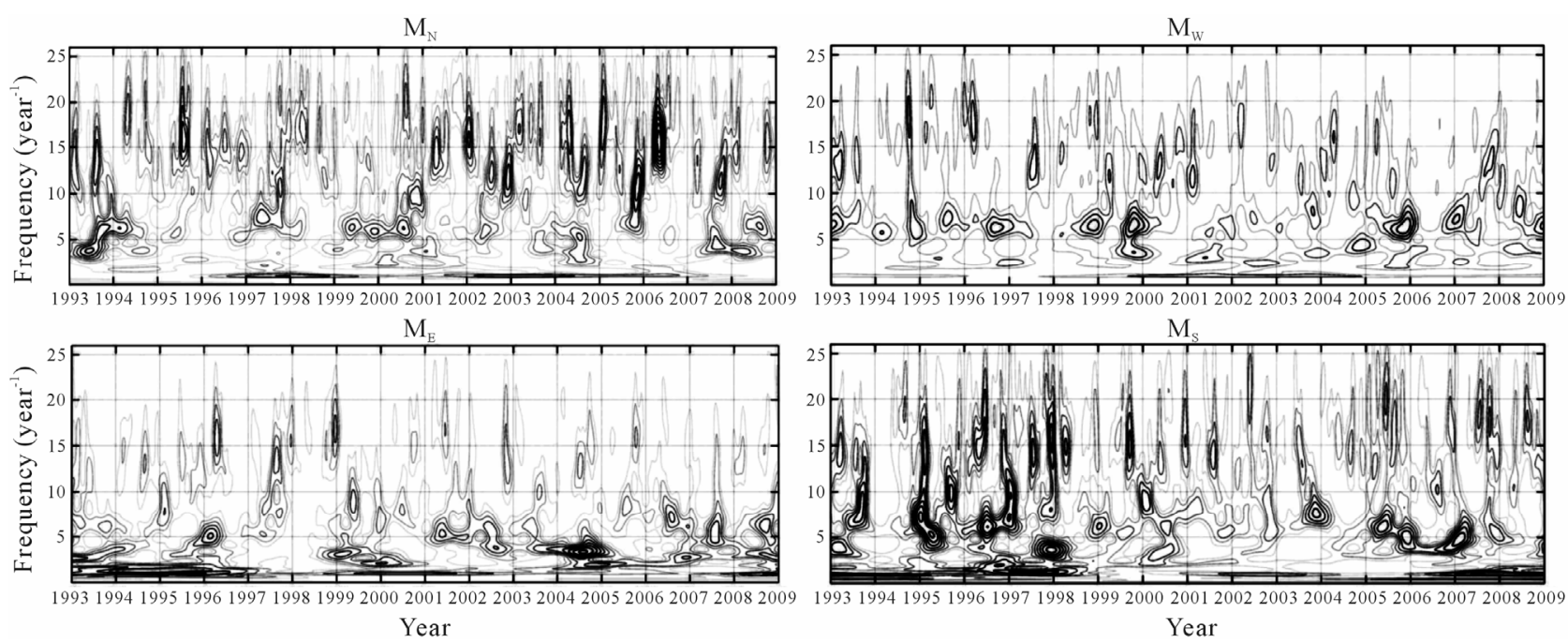

Figure 8. Wavelet scalogram from altimeter data.

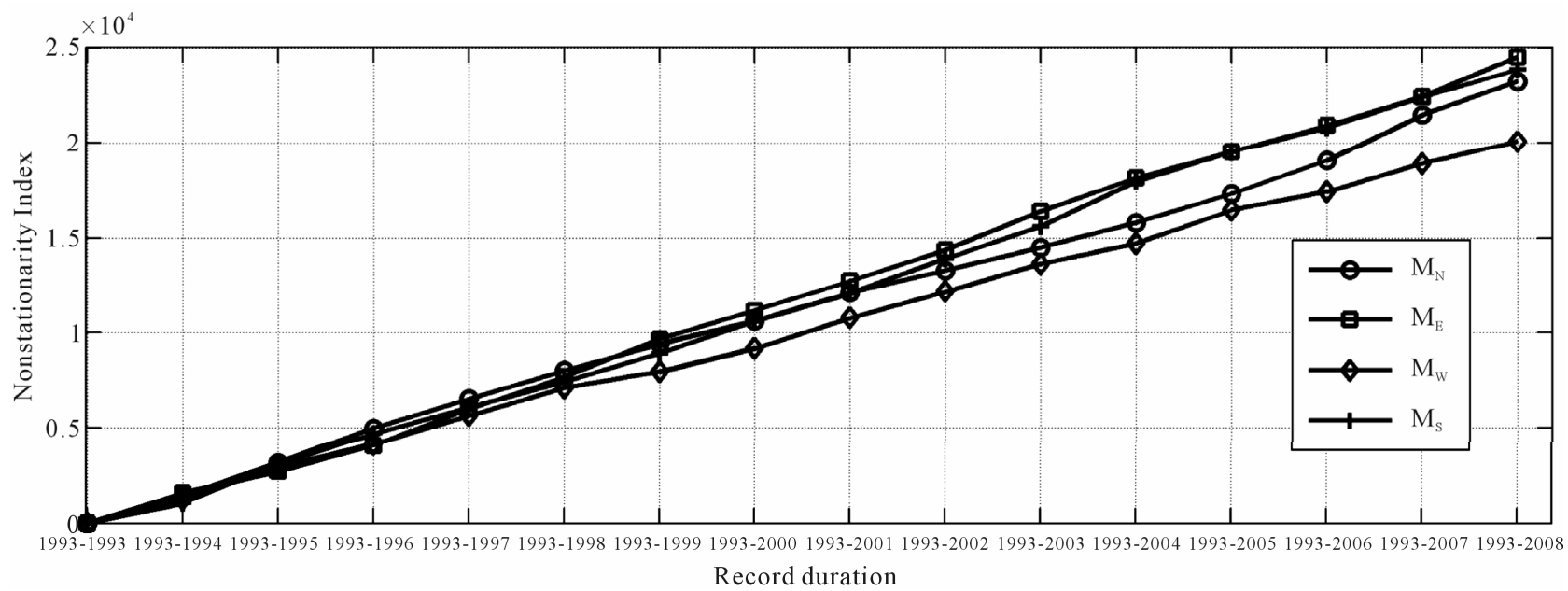

Figure 9. Non-stationarity index calculated from altimeter records. 
regional sea areas around Taiwan, through the analysis of in-situ tide gauge and satellite altimetry records. After calculating the sea level trends from the altimetry records, we revealed similarities in the rates associated with sea level trends calculated in the same sea area. However, differences in the trends of sea level change calculated in different sea areas around Taiwan can be as high as 5 $\mathrm{mm} /$ year.

In addition, sea surface heights around Taiwan are higher than the global mean surface height. It should also be noted that the calculated results between in-situ and altimeter records were quite different in some sea areas around Taiwan. Subsidence and land surface uplift no doubt have a significant influence on the accuracy of calculated sea level trends. We also discussed the probability distribution of sea level records. The results of distribution fitness showed spatial inhomogeneity of sea level records, and differences in the distribution from altimeter time series within the same matrix, particularly in the west sea area of Taiwan.

To reveal the fluctuations in sea level records, we employed various tools incorporating spectral transform. From the results of Fourier spectra, we confirmed a number of obvious fluctuations in the sea level records. Annual fluctuations in most of the sea level records from altimeter and in-situ tide gauge records were quite obvious, and a few of the astronomical tide constituents were observed in the Fourier spectra. In addition to the Fourier spectra, we discussed the non-stationary features of sea level time series according to wavelet scalograms. The energy density from various frequency bands showed non-stationarity in the time series of altimeter records. The non-stationarity indices calculated from the wavelet scalograms showed that the sea level oscillations were more non-stationary in the sea area of eastern Taiwan than they were in other sea areas around Taiwan.

\section{Acknowledgements}

This work was supported by the Water Resources Agency (MOEAWRA0990248) and the National Science Council (NSC 98-2923-I-006-001-MY4 and NSC 1002221-E-006-020) in Taiwan. The authors would like to offer their sincere thanks to the agencies.

\section{REFERENCES}

[1] D. Reeve, A. Chadwick and C. Fleming, "Coastal Engineering: Processes, Theory, and Design Practice,” Spon Press, New York, 2004.

[2] S. Dasgupta, B. Laplante, C. Meisner, D. Wheeler and J. Yan, "The Impact of Sea Level Rise on Developing Countries: A Comparative Analysis," Climatic Change, Vol. 93, No. 3-4, 2009, pp. 379-388.

\section{doi:10.1007/s10584-008-9499-5}

[3] J. A. Church and N. J. White, "A 20th Century Acceleration in Global Sea-Level Rise,” Geophysical Research Letters, Vol. 33, 2006, pp. 1-4.

[4] Y. H. Tseng, L. C. Breaker and E. T. Y. Chang, "Sea Level Variations in the Regional Seas around Taiwan," Journal of Oceanography, Vol. 66, No. 1, 2010, pp. 27 39. doi:10.1007/s10872-010-0003-2

[5] A. Cazenave, K. Dominh, F. Ponchaut, L. Soudarin, J. F. Cretaux and C. Le Provost, "Sea Level Changes from Topex-Poseidon Altimetry and Tides Gauges, and Vertical Crustal Motions from DORIS," Geophysical Research Letters, Vol. 26, No. 14, 1999, pp. 2077-2080. doi:10.1029/1999GL900472

[6] J. L. Chen, C. R. Wilson, B. D. Tapley and T. Pekker, "Contributions of Hydrological Processes to Sea Level Change," Physics and Chemistry of the Earth, Vol. 27, No. 32-34, 2002, pp. 1439-1443. doi:10.1016/S1474-7065(02)00088-8

[7] N. J. White, J. A. Church and J. M. Gregory, "Coastal and Global Averaged Sea Level Rise for 1950 to 2000," Geophysical Research Letters, Vol. 32, 2005, pp. 1-4.

[8] http://www.aviso.oceanobs.com/duacs/

[9] R. M. Ponte, "Low-Frequency Sea Level Variability and the Inverted Barometer Effect," Journal of Atomspheric and Oceanic Technology, Vol. 23, No. 4, 2006, pp. 619629. doi:10.1175/JTECH1864.1

[10] C. Wunsch and D. Stammer, "Atmospheric Loading and the Oceanic Inverted Barometer Effect,” Reviews of Geophysics, Vol. 35, No. 1, 1997, pp. 79-107. doi:10.1029/96RG03037

[11] M. Ablain, A. Lombard, N. Picot and A. Cazenave, "Error Estimation of the Global and Local Mean Sea Level Trends from Jason-1\&2 and T/P Data,” Communication at Ocean Sciences Symposium, Portland, 22-26 February 2010.

[12] Subsidence of Various Regions around Taiwan. http://www.wra.gov.tw/public/Data/sovr.htm

[13] S. B. Yu and L. C. Kuo, "Present-Day Crustal Motion along the Longitudinal Valley Fault, Eastern Taiwan," Tectonophysics, Vol. 333, No. 1-2, 2001, pp. 199-217. doi:10.1016/S0040-1951(00)00275-4

[14] B. C. Lee, L. C. Wu, D. J. Doong and C. C. Kao, "Seasonal Variations of Wind and Wave Data over Taiwan Waters,” Marine Geophysical Researches, Vol. 28, No. 3, 2007, pp. 183-190. doi:10.1007/s11001-007-9025-6

[15] Z. H. C. Laurence, L. C. Wu, D. J. Doong and C. C. Kao, "Two-Dimensional Continuous Wavelet Transform of Simulated Spatial Images of Waves on a Slowly Varying Topography,” Ocean Engineering, Vol. 35, No. 10, 2007, pp. 1039-1051.

[16] R. J. Marks, "Handbook of Fourier Analysis \& Its Applications,” Oxford University Press Inc., Oxford, 2009.

[17] P. C. Liu, "Is the Wind Wave Frequency Spectrum Outdated," Ocean Engineering, Vol. 27, No. 5, 2000, pp. 577 588. doi:10.1016/S0029-8018(98)00074-2 